\title{
Study on the effect of professional sports clothing on sports physiology.
}

\author{
Zhiwei $\mathbf{L i}^{1^{*}}$, Yong Wang ${ }^{2}$ \\ ${ }^{1}$ Department of Physical Education, Hunan University of Commerce, PR China \\ ${ }^{2}$ Department of Immunology, School of Basic Medical Science, Xiangya School of Medicine, Central South University, \\ PR China
}

\begin{abstract}
With the movement of the whole people and the development of competitive sports, the science and technology investment of sports equipment is increasing in each country, and there are a lot of high performance sports clothes with special function. As a kind of high performance sports equipment, wicking professional sports clothing is very popular with athletes and fitness enthusiasts, and its impact on sports physiology is also a hot research topic at home and abroad. Based on this, from the professional sports clothing on the impact of the heat and moisture dissipation, the impact of thermal stress on the exercise physiology was studied, and two sets of professional sports wear of $\mathrm{C} 1$ and $\mathrm{C} 2$ were designed. The thermal manikin was studied and the analysis of thermal resistance, moisture resistance and permeability index of sports clothing were conducted. Prediction of heat (PHS) model was used to predict and analyse changes of physiological indexes such as skin temperature, sweating rate and total sweat of human body of professional sports clothing and ordinary polo shirt after wearing in five different environments, and the heat regulation effect of professional sports clothing on human body under different environment was obtained. Practice has proved that wearing professional sports clothing can effectively reduce the body's sweat volume, lower body temperature, prolong the duration of movement.
\end{abstract}

Keywords: Effect, Sports clothing, Sports physiology.

\section{Introduction}

The heat exchange of the human body and the surrounding environment depends on the state of the human body and the environment around the climate, but it is also affected by the physical properties of clothing to a large extent. Clothing is an interactive medium of heat exchange between the surrounding environment and the human body. The clothing is not just a passive cover for the skin, but it can make the interaction with the skin heat regulating function changed with different motion states, and it is the dynamic media of heat and moisture transfer in human body which needs to maintain a constant internal temperature and the environment.

Sousa believes that the human body is an open body system with a strong adaptability. In sports, the body produces heat to provide muscle energy, promote muscle activity, but because lack of metabolism will lead to the accumulation of heat, the heat these muscles cannot consume must be released in order to prevent the malignant rise in the body temperature [1]. When the environment changes, the body's fastest adaptive response is the change of the circulatory system, which carries the heat generated in the body to the skin, through sweating to increase heat dissipation [2]. Research on moisture sportswear is mainly focused on the thermal physiology of different fibre materials [3]. Nazir et al. studied the exercise of $27^{\circ} \mathrm{C}$ in pure cotton and pure polyester. The strength was $50 \%$ of the maximum oxygen consumption was 4 times, $10 \mathrm{~min}$ for each time. The results show that compared with the pure cotton fabric, the average pulse in polyester sportswear was higher, faster increase in rectal temperature, and the average skin temperature of the polyester sportswear with high permeability was markedly higher than that of the polyester fabric with low permeability [4]. The researchers later raised the environmental temperature and humidity, or improved the exercise intensity to further explore the effect of different materials on the exercise physiology [5]. Chau made a study with the environmental temperature and humidity rising to $30^{\circ} \mathrm{C}$ and $50 \% \mathrm{RH}$. The study showed that the average skin temperature of the polyester fabric with the wind speed of $1.5 \mathrm{~m} / \mathrm{s}$ was markedly higher than that in the other state. At the same time, when wearing a cotton blend the temperature was markedly lower than that of other states, and the micro climate of chest back temperature was lower than that in other state [6]. Thoresen increased the exercise intensity, and the results of the study showed that when wearing fibre sportswear, sweating was with higher efficiency, less sweat retention rate, that was to say compared to cotton sportswear, fibre sportswear could promote the evaporation of sweat, but heart rate, oxygen consumption, 
skin temperature and body temperature would not have a marked difference [7].

With the development of new textile materials and textile technology, new spinning technique has combined the advantages of chemical fibre and natural fibre, blended fabric is more and more used in wicking sportswear [8]. Lama et al. reported that the average skin temperature of the subjects when wearing chemical fibre was lower than that of wearing chemical fibre during and after the exercise [9]. Lucia et al. studied the changes of the heat physiological index of subjects wearing soybean protein fibre and cotton fibre blended fabric (50\% soybean fibres, $50 \%$ cotton or cotton fabric) on at $20^{\circ} \mathrm{C}$ during exercise. It was found that compared with that of pure cotton sportswear, lower temperature and humidity of microclimate occurred in soybean blended sportswear, moisture transfer performance was better, and it had a marked influence on the increase to prevent water vapour pressure [10]. Malina et al. showed that sweating rate and sweat retention rate are lower when subjects wearing polyester tshirt, and the skin temperature in the polyester shirt during the recovery phase after the exercise could return to the level of exercise faster [11]. Therefore, this research analyses the influence of professional sports clothing on exercise physiology by the thermal manikin, which can contribute to the overall fitness in China.

\section{Materials and Methods}

\section{Heat balance of the human body under the movement}

The human body is through the heat production and heat dissipation to regulate the temperature. Heat production of the body: how much heat production depends on the intensity of tissue metabolism, and the movement heat production under the different intensity can increase 10-15 times of quiet state [12]. When the human body is quiet, the liver is the main organ of heat production. During exercise, the muscles are the main heat producing organs. For the body's heat dissipation, the heat generated by the body is through the blood to the skin tissue, through conduction, convection, radiation, evaporation of several ways to distribute in vitro.

Conduction is the exchange of heat by direct contact with another object. Convection is one of the major types of heat transfer. Radiation is heat dissipation through electromagnetic wave infrared, which is the primary way usually body heat loss. Evaporative cooling is a way to dissipate the body heat through the evaporation of water. According to the test calculations, when a person is quiet, the body produces 1,500 calories per min. In the on-going exercise with $70 \%$ of the maximum oxygen uptake intensity, a kcal of heat can be produced each minute. The heat sink ratio in a different state of this person is as shown in Table 1 .

Table 1. The quiet with motion rate of the cooling way.

\begin{tabular}{|c|c|c|c|c|}
\hline The cooling way & $\begin{array}{l}\text { Quiet } \\
(\%)\end{array}$ & $\mathrm{Kcal} / \mathrm{min}$ & $\begin{array}{l}\text { Movement } \\
(\%)\end{array}$ & $\mathrm{Kcal} / \mathrm{min}$ \\
\hline
\end{tabular}

\begin{tabular}{lcccc}
\hline Conduction and convection & 20 & 0.3 & 15 & 2.2 \\
\hline Radiation & 60 & 0.9 & 5 & 0.8 \\
\hline The evaporation & 20 & 0.3 & 80 & 12 \\
\hline
\end{tabular}

In the complex heat exchange process of human-clothingenvironment system, clothing can be regarded as the body extension between human skin and the environment, which can not only play a role of heat resistance (insulation), but also has the effect of heat transfer.

The thermal resistance and moisture resistance are the important factors influencing the thermal equilibrium. Thermal resistance is the thermal resistance force of clothing because of temperature, which is the ratio of the temperature difference between the two sides of the garment layer and the unit area. Thermal resistance can make the good evaluation on the thermal insulation capacity that clothing has [13]. Wet resistance is moisture resistance performance of clothing, which refers to the ratio of water vapour pressure and heat flow rate per unit area of evaporation on both sides of the clothing layer. Wet resistance has a great effect on clothing complex comfortable. The humidity of the environment, the movement of the human body, the permeability and moisture absorption of the clothing all affect the wet resistance of the garment.

\section{Design principles of professional sportswear}

Considering the performance, the air layer, clothing comfort, comprehensive strength and other factors of various wicking fabric clothing, the overall of sportswear is designed with no collar waist design, but high body fitting degree, which can reduce the clothing thermal resistance and moisture resistance, and decrease the resistance in the process [14]. In the process of movement, the motion of the upper arm is larger, so the short uses cotton fabric with excellent elasticity, which can fit with upper arm muscles. In the process of movement, hot and wet sites of the human body are the chest part and the back part. The 2 parts of professional sports use cool max and cool dry moisture absorbing and quick drying fabric stitching, which can make human sweat send out as soon as possible, speed the heat transfer, and improve the thermal and moisture comfort of sportswear [15]. The temperature of abdomen buttocks and waist side is not high, and sweating is also small, so mesh fabric is used with high permeability, and the outside air convection can help chest and back parts perspiration cooling.

\section{The effect of thermal stress on exercise physiology}

In the movement, venous blood volume will increase, muscle blood circulation decrease, and increasing heart rate is only way to compensate the shortage of blood. In addition, the increase of perspiration, blood concentration, and blood viscosity will result in the reduction of the returned blood volume, the increase of heart burden and thus reduce the work efficiency. In the severe dehydration, the plasma norepinephrine concentration in blood increases markedly, causing that the skin blood vessels can be transformed into 
contraction by relaxation. The contraction of the skin blood vessel further reduces the body heat dissipation ability, which can make the heart temperature rise, and the contractility of the heart is weakened. The compensatory increase in heart rate is not enough to compensate for the decrease in stroke volume, thus reducing the ability to movement [16].

Body temperature regulation: Exercise in high temperature environment can accelerate the sweat out of the body heat, which is the main way to maintain the body heat balance. Due to the large number of perspiration and loss of a certain amount of $\mathrm{Na}+, \mathrm{K}+, \mathrm{Cat}+, \mathrm{Fe}^{2+}, \mathrm{Mg}^{2+}, \mathrm{Zn}^{2+}$ and other trace elements, it can decrease the exercise ability. When the ambient temperature exceeds the skin temperature, while the heat capacity is affected, it can lead to excessive body temperature [17]. In high intensity exercise, the temperature of the motor muscles is often higher than the body temperature, which can affect the function of skeletal muscle, result in fatigue and affect the metabolism of the body.

In the movement of thermal environment, if the dress hinders the heat loss, it will not only reduce the exercise capacity, but also may increase risk of thermal damage to the wearer, so it is very essential to select sportswear that can help to maintain the thermal balance. Wicking sportswear can quickly absorb the sweat and evaporate quickly spread into the environment, maintain the skin the vapour pressure difference between the environment, which is conducive to evaporative cooling. On the other hand, it can maintain the relative drying of the skin and movement, so that the wearer feels comfortable.

\section{Test system of thermal manikin}

The thermal resistance and moisture resistance of wicking pants are measured through thermal manikin. This dummy has 34 independent heating sections and multiple sweaty holes with uneven density distribution, which can measure thermal resistance and moisture resistance in different motion states of different environment. In order to compensate for the lack of physical index test of thermal manikin and make it more close to the physiological state of reality, through real experiments on the basis of previous studies, the thermal comfort evaluation model is established, namely Fiala model. This model allows the sweating manikin to simulate the thermal physiology reaction reality, namely heat and sweating. Combine with RadTherm thermal analysis software to calculate the corresponding thermal comfort and feel [18]. The thermal manikin is combined with Fiala thermal regulation model. When using this software to do the comfort test, it only needs to set the ambient temperature and humidity, and input corresponding metabolic heat production according to the intensity of the exercise, thermal physiological indicators such as the body temperature, skin temperature, sweating rate and thermal comfort can be obtained.

\section{Measurement of thermal resistance and wet resistance}

According to ISO-15831 (2004), constant skin temperature model is used ( $\mathrm{T}_{\text {manikin }}$ is $34^{\circ} \mathrm{C}$ ) to measure thermal resistance in clothing under the condition of constant temperature and humidity. Air temperature is $(20+0.5)^{\circ} \mathrm{C}$, the relative humidity is $(65+5) \%$, and the wind speed is $(0.4+0.5) \mathrm{m} / \mathrm{s}$. The dummy dresses in sportswear, wearing cotton underwear and knitted shorts, and the foot wear shoes experiment. Measure the index for 3 times of per garment. The total thermal resistance $\left(\mathrm{I}_{t}\right)$ is calculated by parallel method, as shown in the formula (1). The calculation of the intrinsic thermal resistance $\left(\mathrm{I}_{\mathrm{cl}}\right)$ is as shown in the formula (2). Because clothing studied is the fit clothing, $\mathrm{f}_{\mathrm{cl}}$ has little influence on the inherent thermal resistance of clothing, so it is assumed that the $f_{c l}$ is 1 .

$$
\begin{aligned}
& I_{t}=\frac{6.45 \times\left(\bar{T}_{s k}-T_{a}\right)}{\sum A_{i} H_{i} / A} \rightarrow(1) \\
& I_{c l}=I_{t}-I_{a} / f_{c l} \rightarrow(2)
\end{aligned}
$$

In the above formula: It and Ia are the total thermal resistance of the boundary layer of air clothing and, clo; Icl is the inherent thermal resistance of clothing, clo; $\bar{T}_{s k}$ and Ta is, respectively, average skin temperature and ambient temperature, ${ }^{\circ} \mathrm{C}$; and $\mathrm{Hi}$ is the amount of heat dissipation in the $\mathrm{i}$ segment, $\mathrm{W} / \mathrm{m} 2$; $\mathrm{Ai}$ is the surface area of the i segment, $\mathrm{A}$ is a skin surface area, $\mathrm{m} 2$; $\mathrm{fcl}$ is clothing area factor.

According to ASTM F 2370 (2010), constant skin temperature model is used $\left(\mathrm{T}_{\text {manikin }}=\mathrm{T}_{\text {air }}=34^{\circ} \mathrm{C}\right)$ to measure thermal resistance in clothing under the condition of constant temperature and humidity. Air temperature is $(34 \pm 0.5)^{\circ} \mathrm{C}$, the relative humidity is $(40 \pm 15) \%$, and the wind speed is $(0.4 \pm$ $0.1) \mathrm{m} / \mathrm{s}$. Dress of dummy is the same with thermal resistance test. At the end of each test, sweat clothes are be dried to prepare for the next experiment. Measure the index for 3 times of per garment. The wet resistance of clothing is calculated by the method of heat dissipation, as shown in the formula (3). The formula (4) is used to calculate the permeability index of clothing.

$R_{e t}=\frac{\left(p_{s k}-p_{a}\right)}{\sum A_{i} H_{i} / A}$

$i_{m}=\frac{I_{t}}{6.45 \times 0.0165 \times R_{e t}}$

In the above formula: $\mathrm{R}_{\mathrm{et}}$ is the total wet resistance, $\mathrm{Pa} . \mathrm{m}^{2} / \mathrm{W}$; $\mathrm{P}_{\text {sk }}$ and $\mathrm{P}_{\mathrm{a}}$ is, respectively, the water vapour pressure of wet fabric skin and ambient, $\mathrm{P}_{\mathrm{a}} ; \mathrm{H}_{\mathrm{i}}$ is the evaporation heat of the $\mathrm{i}$ body section, $\mathrm{m}^{2} / \mathrm{W} ; \mathrm{A}_{\mathrm{i}}$ is the surface area of the $\mathrm{i}$ body section; $A$ is the total surface area of skin, and $i_{m}$ is the permeability index. Table 2 lists the clothing thermal resistance, moisture resistance and permeability index. The results show that the thermal resistance and moisture resistance of $\mathrm{C} 1$ and $\mathrm{C} 2$ are less than that of $\mathrm{C} 3$, while the permeability index is greater than $\mathrm{C} 3$, and there is no marked difference between $\mathrm{C} 1$ and $\mathrm{C} 2$.

Table 2. Thermal insulation and evaporative resistance.

\begin{tabular}{llll}
\hline Clothing $\quad \mathrm{I}_{\mathrm{t}} / \mathrm{clo}$ & $\mathrm{I}_{\mathrm{cl}} / \mathrm{clo}$ & $\mathrm{R}_{\mathrm{et}} / \mathrm{Pa} \cdot \mathrm{m}^{2} / \mathrm{W}$ & $\mathrm{i}_{\mathrm{m}}$
\end{tabular}




\begin{tabular}{lllll}
\hline C1 & 0.88 & 0.26 & 19.7 & 0.43 \\
\hline C2 & 0.89 & 0.27 & 20.19 & 0.43 \\
\hline C3 & 0.99 & 0.37 & 28.9 & 0.33 \\
\hline
\end{tabular}

exercise 1, rest, exercise 2 and rest. Table 4 shows 5 experimental conditions.

Table 3. Simulated activity.

\section{The physiological indexes predicted by using PHS model}

PHS model is used to predict the physiological indexes of 3 pieces of clothing in different environments, including skin temperature, core temperature, sweating rate, and total amount of sweating. Table 3 shows the simulated motion state. The whole experiment is divided into 5 stages, namely, rest,

\begin{tabular}{llll}
\hline Time slot & Time/minute & Motion state & Metabolic rate/(W.m-2 \\
\hline T1 & 10 & Rest & 70 \\
\hline T2 & 45 & Exercise 1 & 250 \\
\hline T3 & 20 & Rest & 70 \\
\hline T4 & 45 & Exercise 2 & 250 \\
\hline T5 & 20 & Rest & 70 \\
\hline
\end{tabular}

Table 4. Environmental conditions for simulation.

\begin{tabular}{|c|c|c|c|c|c|}
\hline Code & Condition & $\begin{array}{l}\text { Vapour pressure of } \\
\text { water/ } \mathrm{KP}_{\mathrm{a}}\end{array}$ & Temperature $/{ }^{\circ} \mathrm{C}$ & Relative temperature $/ \%$ & Wind speed $/\left(\mathrm{ms}^{-1}\right)$ \\
\hline E1 & High temperature and high temperature & 4 & 34 & 75 & 0.4 \\
\hline E2 & High temperature and low humidity & 2 & 34 & 38 & 0.4 \\
\hline E3 & Warm and high humidity & 2 & 25 & 63 & 0.4 \\
\hline E4 & Warm humidity & 1 & 25 & 32 & 0.4 \\
\hline E5 & Normal atmospheric temperature & 1 & 20 & 43 & 0.4 \\
\hline
\end{tabular}

\section{Results}

\section{Skin temperature}

From $30 \mathrm{~min}$, the skin temperature of $\mathrm{C} 3$ is markedly higher than the other 2 pieces of clothing, especially after $75 \mathrm{~min}$ and in $120 \mathrm{~min}$ it reaches the maximum value (about $36.9^{\circ} \mathrm{C}$ ). After the first exercise $(55 \mathrm{~min})$, the maximum skin temperature difference of $\mathrm{C} 3$ and other clothing is $0.4^{\circ} \mathrm{C}$, and after the second exercise $(120 \mathrm{~min})$, the maximum skin temperature difference is 0.9 .

Under the other 4 kinds of environmental conditions, the changes of human skin temperature show a similar pattern. Table 5 shows the changes in skin temperature of the human body at different environmental conditions.

Table 5. Skin temperature under different conditions ${ }^{\circ} \mathrm{C}$.

\begin{tabular}{llllllll}
\hline Code & $\begin{array}{l}\text { Dress } \\
\text { code }\end{array}$ & 0 & 10 & 55 & 75 & 120 & 140 \\
\hline E1 & C1 & 34.1 & 34.8 & 35.6 & 35.4 & 35.9 & 35.6 \\
\cline { 2 - 7 } & C2 & 34.1 & 34.8 & 35.6 & 35.4 & 36 & 35.6 \\
\cline { 2 - 8 } & C3 & 34.1 & 34.6 & 36.1 & 35.8 & 36.8 & 36.5 \\
\hline E2 & C1 & 34.1 & 34.4 & 35.2 & 34.8 & 35.2 & 34.8 \\
\cline { 2 - 8 } & C2 & 34.1 & 34.4 & 35.2 & 34.7 & 35.2 & 34.7 \\
\hline & C3 & 34.1 & 34.3 & 35.3 & 34.7 & 35.5 & 34.7 \\
\hline E3 & C1 & 34.1 & 33.4 & 34.1 & 33.6 & 34.1 & 33.6 \\
\cline { 2 - 8 } & C2 & 34.1 & 33.4 & 34.1 & 33.6 & 34.1 & 33.6 \\
\hline
\end{tabular}

\begin{tabular}{|c|c|c|c|c|c|c|c|}
\hline & $\mathrm{C} 3$ & 34.1 & 33.4 & 34.4 & 33.7 & 34.4 & 33.7 \\
\hline \multirow[t]{3}{*}{ E4 } & C1 & 34.1 & 33.2 & 34 & 33.4 & 33.8 & 33.4 \\
\hline & $\mathrm{C} 2$ & 34.1 & 33.2 & 33.9 & 33.4 & 33.8 & 33.4 \\
\hline & C3 & 34.1 & 33.3 & 34.2 & 33.5 & 34.2 & 33.5 \\
\hline \multirow[t]{3}{*}{ E5 } & $\mathrm{C} 1$ & 34.1 & 32.6 & 33.2 & 32.8 & 33.2 & 32.8 \\
\hline & $\mathrm{C} 2$ & 34.1 & 32.6 & 33.3 & 32.8 & 33.3 & 32.8 \\
\hline & C3 & 34.1 & 32.8 & 33.7 & 33.1 & 33.8 & 33.1 \\
\hline
\end{tabular}

From Table 5, it can be seen that under high temperature conditions (E1 and E2), in the second movement stage, the skin temperature after wearing sportswear $\mathrm{C} 1$ and $\mathrm{C} 2$ is markedly lower than that of $\mathrm{C} 3$. This shows that the new type of fabric splicing professional sports wear has better heat dissipation performance than ordinary polyester clothing. This may be related to that professional sportswear has less resistance and large permeability index. Human sweat after exercise can quickly be transferred to the garment surface and evaporate on the surface of the body, which can take heat and reduce skin temperature [19]. In addition, compared with the conditions of E1 and E2, it is showed that the lower the environmental humidity, the smaller the moisture transfer resistance of clothing, the more obvious the evaporative cooling effect.

In the warm environment of E4 and E5, in the 2 movement time periods $\mathrm{T}_{2}$ and $\mathrm{T}_{4}$, the skin temperature of $\mathrm{C} 3$ is markedly higher than the other 2 pieces of clothing, and it reaches the maximum value in $120 \mathrm{~min}$. In the stage of rest, the skin temperature of the clothing has no obvious difference. The results showed that under the condition of $25^{\circ} \mathrm{C}$, in the human 
body movement, the professional sports equipment has better heat dissipation performance than the ordinary polyester clothing. Under the condition of $\mathrm{E} 5$, in the motion time periods $\mathrm{T}_{2}$ and $\mathrm{T}_{4}$, the skin temperature of $\mathrm{C} 3$ is markedly higher than the other 4 clothing, but the skin temperature is lower than $34^{\circ} \mathrm{C}$.

\section{Total perspiration}

In the total amount of sweating, the overall trend of the 3 garments is the following: With the extension of time, the total amount of sweating continues to rise, reaching the maximum value in $140 \mathrm{~min}$. Table 6 shows the total amount of sweat in 3 garments under 7 different conditions. From the table, we can see that the total amount of sweat produced by $\mathrm{C} 3$ is larger than that of professional sports clothing $\mathrm{C} 1$ and $\mathrm{C} 2$. With the decrease of the ambient temperature, the total amount of sweat of the skin gradually decreases [20]. The data can be found at high temperature, temperature and humidity, under the same temperature conditions, the greater the humidity, the greater the amount of sweat of the skin, but in the warm temperature conditions, the effect of the relative humidity on the total amount of sweat is not obvious.

Table 6. Total three pieces of clothing sweat under different environment.

\begin{tabular}{llll}
\hline The environment & C1 & C2 & C3 \\
\hline E1 & 1622.3 & 1618.7 & 1764.3 \\
\hline E2 & 1084.3 & 1107.2 & 1321.8 \\
\hline E3 & 649.6 & 652.1 & 738.3 \\
\hline E4 & 637.4 & 642.9 & 692.3 \\
\hline E5 & 448.9 & 454.8 & 504.9 \\
\hline
\end{tabular}

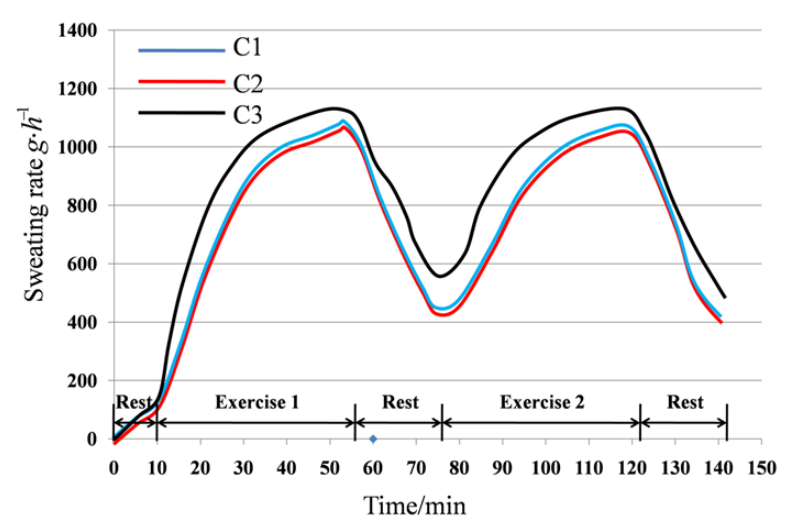

Figure 1. Three pieces of clothing sweating rate under high temperature and high humidity environment.

\section{Sweating rate}

Figure 1 shows the sweating rate of 3 pieces of clothing at $34^{\circ} \mathrm{C}$ and $75 \%$ relative humidity. Under high temperature and high humidity conditions, the sweating rate of the 3 garments all show "m" type. Two peaks are found at the $55 \mathrm{~min}$ and 120 $\mathrm{min}$ in the end of $\mathrm{T}_{2}$ and $\mathrm{T}_{4}$ periods, respectively.

During the entire movement, the minimum sweating rate occurs in $75 \mathrm{~min}$ and $140 \mathrm{~min}$, which is the end of the rest stage $T_{3}$ and $T_{5}$, and the overall sweating rate of C3 is slightly higher than other 2 pieces of clothing.

Taking the high temperature environment as an example, under high temperature and high humidity conditions, the 2 peaks are $1105.8 \mathrm{~g} / \mathrm{h}$ and $1108.2 \mathrm{~g} / \mathrm{h}$ respectively, and the 2 lowest points, is $442.9 \mathrm{~g} / \mathrm{h}$ and $434.6 \mathrm{~g} / \mathrm{h}$, respectively. In the early stage of the exercise period with the metabolic rate of $250(10 \sim 30 \mathrm{~min}$ and 70 90 $\mathrm{min}$ ) as well as the $10 \mathrm{~min}$ after the rest stage, the difference between clothing $\mathrm{C} 3$ and 2 pieces of professional sports clothing $\mathrm{C} 1$ and $\mathrm{C} 2$ is obvious. In high temperature and humidity environment, 2 peaks are $852.7 \mathrm{~g} / \mathrm{h}$ and $860.1 \mathrm{~g} / \mathrm{h}$; the lowest point for $338.0 \mathrm{~g} / \mathrm{h}$ and $339.2 \mathrm{~g} / \mathrm{h}$. From $25 \mathrm{~min}$ to the end of the experiment, the difference of the sweat rate between the clothing $\mathrm{C} 3$ and the 2 professional sports apparel is the most obvious. It can be seen that in the high temperature environment, the relative humidity has a certain effect on the difference between the sweating rates of clothing.

\section{Discussion}

As a commercial high-end sports apparel consumer product, high performance sports clothing has become the preferred equipment of the international top professional athletes in the training or competitive matches with its good auxiliary function and superior comfort performance, and has won highly respect of the majority of sports fans. Hygroscopic good professional sports clothing has broad market prospect, at the same time, it has also become a research hotspot in the field of scientific research. In this paper, a detailed study of the 2 professional sports clothing fabric splicing type is conducted, and the thermal regulation effect of new developed clothing and ordinary polyester clothing under different environmental conditions is evaluated by sweating manikin system and PHS model. The study has found that moisture transfer properties, moisture absorption ability and evaporative cooling effect of professional sports clothing are better than that of the common polyester clothing. Compared to ordinary polyester clothing, on the surface temperature of the skin, sweat amount, sweat rate and other aspects, professional sports clothing has a marked improvement, and professional sports service can effectively reduce the impact of violent movement. Practice shows that professional sports clothing has good wicking ability, and it can effectively reduce the surface temperature of the skin and the athletes sweat rate, which has a positive effect on athlete's physiological responses.

\section{References}

1. Sousa JD, Cheatham C, Wittbrodt M. The effects of a moisture-wicking fabric shirt on the physiological and perceptual responses during acute exercise in the heat. Appl Ergonom 2014; 45:1447-1453. 
2. Dong $\mathrm{Y}$, Kong J, Mu C. Materials design towards sport textiles with low-friction and moisture-wicking dual functions. Materials Design 2015; 88: 82-87.

3. Lee K. Design implementation, fabric analysis, and physiological and subjective testing of a sportswear garment prototype. Kinesiol 2014.

4. Nazir A, Hussain T, Abbas G. Effect of design and method of creating wicking channels on moisture management and air permeability of cotton fabrics. J Nat Fibres 2015; 12: 232-242.

5. Tang KPM, Kan CW, Fan JT. Psychophysical measurement of wet and clingy sensation of fabrics by the volar forearm test. J Sensory Studies 2015; 30: 329-347.

6. Chau KH, Kan CW. Characterizing the trans planar and inplane water transport properties of fabrics under different sweat rate: forced flow water transport tester. Sci Rep 2015; 5.

7. Thoresen T, Lenz M, Gardel M. Reconstitution of contractile actomyosin bundles. Biophysi J 2011; 100: 2698-2705.

8. Beattie GA. Water relations in the interaction of foliar bacterial pathogens with plants. Annual Rev Phytopathol 2011; 49: 533-555.

9. Lama VN, Martinez FJ. Resting and exercise physiology in interstitial lung diseases. Clin Chest Med 2004; 25: 435-453.

10. Lucia A, Earnest C, Perez M. Cancer-related fatigue: can exercise physiology assist oncologists: the lancet oncology. Lancet Oncol 2003; 4: 616-625.

11. Malina, Robert M. Developmental exercise physiology. Am J Human Biol 1996; 28: 526-527.

12. Riddell MC, Perkins BA. Type 1 diabetes and vigorous exercise: applications of exercise physiology to patient management. Can J Diabetes 2006; 30: 63-71.
13. Bendavid M, Williams TM, Ormseth OA. Effects of oiling on exercise physiology and diving behaviour of river otters: a captive study. Can J Zool 2000; 78: 1380-1390.

14. Midgley DAW, Bentley DJ, Luttikholt H. Challenging a dogma of exercise physiology. Sports Med 2008; 38: 441-447.

15. Scott AC, Roe N, Coats A JS. Aerobic exercise physiology in a professional rugby union team. Int J Cardiol 2003; 87: 173-177.

16. Breitbach S, Tug S, Simon P. Circulating cell-free DNA: an up-coming molecular marker in exercise physiology. Sports Med 2012; 42: 565-586.

17. Jr BD. Scientific contributions of A.V. Hill: exercise physiology pioneer. J Appl Physiol 2002; 93: 1567-1582.

18. Jason W, Phillip AB, James MG, Mark TR, Richard GL, Catalina C. Physiological and comfort effects of commercial "wicking" clothing under a bulletproof vest. Int J Industrial Ergonomics. 2007; 7.

19. Eunkyung J, Shinjung Y, Eunae K. Psychophysical determination of moisture perception in high-performance shirt fabrics in relation to sweating level. Ergonomics. $2011 ; 6$.

20. Jill MS, Stephen GH, Glen PK. The influence of active wear worn under standard work coveralls on whole-body heat loss. J Occup Environ Hyg 2011; 8: 652-661.

\section{*Correspondence to}

Zhiwei Li

Department of Physical Education

Hunan University of Commerce

PR China 